\title{
Intraoperative Phase Contrast MRI Analysis of CSF Velocities During Posterior Fossa Decompression for Chiari I Malformation
}

\author{
Nader Delavari, MD, ${ }^{1}$ Anthony C. Wang, MD, ${ }^{2}$ Jayapalli Rajiv Bapuraj, MD,${ }^{3}$ Frank Londy, \\ RTR, ${ }^{3}$ Karin M. Muraszko, MD, ${ }^{1}$ Hugh J.L. Garton, MD, ${ }^{1}$ Cormac O. Maher, MD ${ }^{1 *}$ \\ ${ }^{1}$ Department of Neurosurgery, University of Michigan, Ann Arbor, Michigan, USA \\ ${ }^{2}$ Department of Neurosurgery, University of California Los Angeles, Los Angeles, California, \\ USA \\ ${ }^{3}$ Department of Radiology, University of Michigan, Ann Arbor, Michigan, USA
}

*Address correspondence to: Cormac O. Maher, M.D., Department of Neurosurgery, University of Michigan, 1500 E. Medical Center Drive, Room 3552 TC, Ann Arbor, MI 481095338; Phone: 1-734-647-7960; Fax 1-734-936-9294

E-mail: cmaher@med.umich.edu

Acknowledgments: None

Grant/External Support: None

Conflicts of Interest: None

Running Title: Cerebrospinal Fluid Velocities in Chiari I

This is the author manuscript accepted for publication and has undergone full peer review but has not been through the copyediting, typesetting, pagination and proofreading process, which may lead to differences between this version and the Version of Record. Please cite this article as doi: $10.1002 /$ jmri.26953

This article is protected by copyright. All rights reserved. 


\title{
Intraoperative Phase Contrast MRI Analysis of CSF Velocities During Posterior Fossa Decompression for Chiari I Malformation
}

\author{
Nader Delavari, MD, ${ }^{1}$ Anthony C. Wang, MD, ${ }^{2}$ Jayapalli Rajiv Bapuraj, MD, ${ }^{3}$ Frank Londy, \\ RTR, ${ }^{3}$ Karin M. Muraszko, MD, ${ }^{1}$ Hugh J.L. Garton, MD, ${ }^{1}$ Cormac O. Maher, $\mathrm{MD}^{1 *}$ \\ ${ }^{1}$ Department of Neurosurgery, University of Michigan, Ann Arbor, Michigan, USA \\ ${ }^{2}$ Department of Neurosurgery, University of California Los Angeles, Los Angeles, California, \\ USA \\ ${ }^{3}$ Department of Radiology, University of Michigan, Ann Arbor, Michigan, USA
}

\begin{abstract}
*Address correspondence to: Cormac O. Maher, M.D., Department of Neurosurgery, University of Michigan, 1500 E. Medical Center Drive, Room 3552 TC, Ann Arbor, MI 481095338; Phone: 1-734-647-7960; Fax 1-734-936-9294

E-mail: cmaher@med.umich.edu
\end{abstract}

Acknowledgments: None

Grant/External Support: None

Conflicts of Interest: None

Running Title: Cerebrospinal Fluid Velocities in Chiari I

This article is protected by copyright. All rights reserved. 
This article is protected by copyright. All rights reserved. 


\title{
Intraoperative Phase Contrast MRI Analysis of CSF Velocities During Posterior Fossa Decompression for Chiari I Malformation
}

\begin{abstract}
Background: Cerebrospinal fluid (CSF) velocity at the craniovertebral junction (CVJ) is known to be altered in patients with Chiari I malformation (CMI), and normalization of CSF velocities is associated with symptom resolution. However, preoperative and intraoperative prediction methods have thus far failed to identify patients in whom CSF velocities can be normalized with posterior fossa decompression (PFD) without duraplasty. Phase contrast MRI (PC-MRI) may assist not only in diagnosis of CMI but also in guiding the intraoperative decision to perform duraplasty during PFD.
\end{abstract}

Purpose: To use intraoperative MRI data to quantify changes in CSF hydrodynamics at the CVJ during each step of PFD with duraplasty (PFDD) in 12 consecutive patients.

Study Type: Retrospective case series with all patients imaged before, during and after decompression, and all data analyzed postprocedure.

Population/Subjects: Pediatric patients, mean age 14 years (range 4-18), undergoing PFD for CMI.

Field Strength/Sequence: Intraoperative studies involved a dedicated 1.5T Siemens MRI imager. PC-MRI scans were in the axial plane at the CVJ.

This article is protected by copyright. All rights reserved. 
Assessment: Two observers assessed measurements.

Statistical Test: The equality of matched pairs of observations was tested using the Wilcoxon matched-pairs signed-ranks test.

Results: Data analyses of the PC-MRI demonstrated a marked and immediate increase in CSF velocity at the posterior CVJ during PFDD. Mean cranially-directed velocities increased by a mean of $1.049 \mathrm{~cm} / \mathrm{s}(P=0.028)$ from pre-incision to postoperative measurement. There was a mean $0.45 \mathrm{~cm} / \mathrm{s}(P=0.022)$ increase in mean cranial velocity from pre-incision to bone decompression scans, and a mean $0.48 \mathrm{~cm} / \mathrm{s}(P=0.018)$ increase in mean velocity from preincision to duraplasty.

Conclusion: In all subjects, significant increases in the mean and peak velocities of craniallyand caudally-directed velocities were observed from pre-incision to post-PFDD scans at the posterior CVJ.

Keywords: Phase contrast MRI; Cerebrospinal fluid; Chiari I malformation; Intraoperative MRI; Posterior fossa decompression; CSF velocity and flow

Abbreviations: $\mathrm{CMI}=$ Chiari type I malformation; $\mathrm{CSF}=$ cerebrospinal fluid; $\mathrm{CVJ}=$ craniovertebral junction; MV = mean velocity; PC-MRI = phase contrast MRI; PFD = posterior 
fossa decompression; PFDD = posterior fossa decompression with duraplasty; $\mathrm{PV}=$ peak velocity; ROI = region of interest 


\section{INTRODUCTION}

Recent phase contrast magnetic resonance imaging (PC-MRI) studies of cerebrospinal fluid (CSF) hydrodynamics have advanced our understanding of the elusive pathophysiology of Chiari I malformation (CMI), an ongoing subject of investigation for over a century.(1,2) Nearly a decade before the early autopsy studies of Hans Chiari, Theodor Langhans noted obstruction at the foramen magnum by the cerebellar tonsils to be associated with creation of a cavity in the spinal cord.(3,4) Over a half century later, Gardner proposed that the fourth ventricle outflow obstruction in CMI leads to the diversion of CSF through the obex into the central canal.(5) Williams hypothesized that the cerebellar tonsils descend and plug the subarachnoid space during cardiac systole.(6,7) Evidence from PC-MRI studies of CSF velocities has not supported Gardner's hypothesis, but instead suggest that the piston-like pulsation of the cerebellar tonsils leads to increased pulsation within the spinal cord that contributes to syrinx formation.(1)

CMI remains a challenging clinical entity, manifesting in a broad range of signs and symptoms, including headache, neck pain, vertigo, sensory changes, apnea, ataxia, and syrinx formation.(8) On MRI, CMI is characterized by $5 \mathrm{~mm}$ of tonsillar ectopia below the foramen magnum. However, as the position of cerebellar tonsils follows a natural distribution in the asymptomatic general population, there are many individuals with tonsillar ectopia without the

pathophysiology of CMI.(9) While sagittal T2-weighted MRI sequences reveal the morphologic abnormalities of CMI, they fail to characterize the aberrations in CSF dynamics. Patients with 
CMI may have abnormalities in CSF dynamics that do not correlate with the degree of morphologic abnormality seen on anatomical imaging studies.

Several important qualities of CSF velocity in CMI have been observed with PC-MRI. Investigators have found significant differences between CSF velocity at the foramen magnum when comparing CMI patients and normal subjects and CMI patients after decompression.(1012) Normalization of CSF velocity at the posterior craniovertebral junction (CVJ) following posterior fossa decompression (PFD) is associated with symptom resolution.(10)

PC-MRI may assist not only in diagnosis of CMI but also in guiding surgical intervention. Although there is wide variation in surgical practice patterns, the surgical treatment of CMI typically includes PFD with an occipital craniectomy and removal of the posterior arch of the first cervical vertebra. Many neurosurgeons also perform further decompression with dural patch grafting (PFDD).(13) However the indications to perform duraplasty are controversial, as some patients may achieve symptom resolution without duraplasty and thereby avoid the associated risks of pseudomeningocele, meningitis, or neurologic injury.(14,15) Preoperative imaging techniques to select patients for bone-only decompression based on extent of tonsillar descent and presence of syringomyelia have not been shown to reduce the rate of re-operation requiring duraplasty.(14) Intraoperative ultrasound has been used to observe characteristics of CSF velocities during PFD to determine the adequacy of decompression and the necessity of performing duraplasty.(16,17) The interpretation of decompression with ultrasound is subjective, limiting its reliability and reproducibility in subsequent studies.(16) The purpose of this 
retrospective case series of pediatric patients was to use intraoperative MRI before, during and after PFD with duraplasty to quantify changes in CSF hydrodynamics at the CVJ.

\section{METHODS}

\section{Subjects}

This was a retrospective analysis of cases from the C.S. Mott Children's Hospital of the University of Michigan. Institutional Review Board approval was obtained for waiver of consent, per HUM00074794. The results of 12 patients with CMI who underwent PFDD with an intraoperative MRI between 2013 and 2015 were reviewed. Patients undergoing PFD without duraplasty were excluded. Only subjects who underwent duraplasty were included in this analysis.

\section{Surgical Procedure}

After induction of general anesthesia, patients were positioned prone with three-point cranial fixation. All patients underwent an initial PC-MRI after anesthesia induction and operative positioning. A small suboccipital craniectomy $(2 \mathrm{~cm}$ superiorly from the foramen magnum) with removal of the posterior arch of the first cervical vertebra was then performed. The posterior atlanto-occipital ligament was then incised and stripped away, and the outer leaf of dura thinned. As is routine in our practice, ultrasound was used to estimate the adequacy of decompression, based on the presence or resolution of tonsillar piston-like pulsation. At this 
time, PC-MRI scans were also acquired to evaluate the restoration of CSF pocket at the site of the tonsils. If further surgical intervention was deemed necessary, based on MRI evaluation and ultrasound, duraplasty with periosteal autograft or synthetic graft was performed. Postoperative MRI sequences were acquired following duraplasty or wound closure.

\section{Image Processing}

The dedicated sequences for the assessment of Chiari I malformations included conventional T2 sagittal and PC-MRI evaluations. These sequences are embedded in the protocols for evaluation of all Chiari I patients. Specifically, the intraoperative studies were performed on a dedicated 1.5T intraoperative MRI imager (Magnetom Espree MRB19, Siemens, Malvern, PA). PC-MRI scans were performed perpendicular to the CVJ. Scan parameters were as follows: $\mathrm{TR} / \mathrm{TE}=40.40 / 12.5 \mathrm{msec}$, averages $=1$, flip angle $=10^{\circ}, \mathrm{FOV}=$ 244 x 244 mm, 252 x 179 matrix, 5-mm sections, with flow compensation. Nine to 24 temporal phases during the cardiac cycle were acquired using a cardiac gated signal for retrospective triggering and depended on the heart rate. Velocity encoding was optimized per patient (6-20 $\mathrm{cm} / \mathrm{s})$.(18) Scan parameters for the sagittal T2-weighted images used as a localizer scout image were as follows: $\mathrm{TR} / \mathrm{TE}=5330 / 96 \mathrm{msec}$, averages $=3$, flip angle $=150^{\circ}, \mathrm{FOV}=308 \times 270 \mathrm{~mm}$, slice thickness $=2.5 \mathrm{~mm}$. Total scan times for the entire set of MRI sequences ranged from 12 to 16 minutes, which included time to prep and position the patient's head in the magnet. It is 
pertinent to note that the scan times varied depending on the hemodynamic parameters of these patients under anesthesia. All vital parameters were constantly monitored for all patients.

CSF peak velocity (PV) and mean velocity (MV) measurements were obtained with Argus software (Siemens, Malvern, PA). PV is defined as the greatest velocity in a region of interest (ROI). MV is the average of all the measured velocities in an ROI. The amplitude of PV is the difference between the greatest positive velocity and the greatest negative velocity. An ROI was selected at the posterior CVJ. Per convention, positive values were assigned to CSF velocities in the cranial direction, and negative values to velocities in the caudal direction.(19) During CSF diastole, CSF moves in the caudocranial direction (positive velocity), whereas during CSF systole, CSF moves in the craniocaudal direction (negative velocity).

ROIs were manually selected to include only the CSF spaces and excluded brain parenchyma and the vertebral arteries at the CVJ. The ROIs were first placed by a medical student (ND) and then verified for accuracy by a Board-certified neuroradiologist (JRB). The placement of the ROI was optimized after observing the propagated ROIs throughout the phase images. Minor adjustments to the ROI were made so that all images were free of interference from soft tissue structures such the displaced tonsils and the vertebral arteries (Figs. 1 and 2). Several subjects had severe tonsillar ectopia and no visible CSF space posteriorly at the foramen magnum. In these cases the ROI was positioned below the foramen magnum, at the level of the mid-position of the odontoid, to allow for CSF velocity measurement in the subarachnoid space just below the tip of the descended tonsils. The position of the ROI was kept at a constant level 
throughout pre-incision, bone decompression, duraplasty, and postoperative scans because at each step a scout T2 sagittal image was performed just prior to the acquisition of the PC-MRI sequence. This assisted in near accurate identification of the axial plane on which the ROIs were drawn. In some cases, measurement of CSF velocity was severely affected by artifact or aliasing, and therefore no velocity was measured. For example, 7 subjects had CSF velocity measurements at the posterior CVJ after duraplasty, and 5 subjects did not have measurable PV or MV.

Statistical analyses were performed using Stata software (Statacorp, College Station, TX). The equality of matched pairs of observations was tested using the Wilcoxon matched-pairs signed-ranks test. A $P$ value of 0.05 or smaller was considered significant for this test.

\section{RESULTS}

The mean age was 14 years (range 4-18); 5 patients were male, and 7 were female (Table 1). All patients had tonsillar ectopia greater than $10 \mathrm{~mm}$ (mean $19 \mathrm{~mm}$ ). Nine of the 12 patients had syringomyelia on preoperative MRI. Tables 2 and 3 report the peak and mean velocities, respectively, at the posterior CVJ, and Tables 4 and 5 report the changes in peak and mean velocities, respectively. During PFD, there was an increase in magnitude of velocity of CSF at the posterior CVJ. The increase in velocity occurred at each step of the decompression, but was greatest after duraplasty. Statistically significant increases in both MV and PV of cranially- and caudally-directed velocities were observed from pre-incision to post-PFDD scans at the posterior 
CVJ. At the posterior CVJ, MV of cranially-directed velocities increased by a mean value of $1.049 \mathrm{~cm} / \mathrm{s}(P=0.028)$ from pre-incision to postoperative measurement. There was a mean 0.45 $\mathrm{cm} / \mathrm{s}(P=0.022)$ increase in MV of cranial velocity from pre-incision to bone decompression scans, and a mean $0.48 \mathrm{~cm} / \mathrm{s}$ increase in MV from pre-incision to duraplasty $(P=0.018)$. Likewise, the PV of cranially-directed velocity at the posterior CVJ increased from pre-incision to bone decompression $(0.739 \mathrm{~cm} / \mathrm{s}$ increase, $P=0.0745)$, and from pre-incision to duraplasty $(1.676 \mathrm{~cm} / \mathrm{s}$ increase). Between the patients in whom postoperative PC-MRI was performed immediately after duraplasty and those in whom intraoperative MRI was performed after complete wound closure, there was no statistically significant difference in MV or PV to suggest that closing the soft tissue layers altered CSF hydrodynamics. The mean PV in the caudal direction was $2.154 \mathrm{~cm} / \mathrm{s}$ greater postoperatively compared to pre-incision measurement $(P=$ 0.028).

\section{DISCUSSION}

CSF velocity at the CVJ is known to be significantly altered in CMI patients, and normalization of CSF velocity is associated with symptom resolution in these patients.(10-12) However, preoperative and intraoperative prediction methods have thus far failed to identify patients in whom CSF velocity can be normalized with PFD alone. In the present study, intraoperative PC-MRI demonstrated a marked and immediate increase in CSF velocity at the 
posterior CVJ during PFDD. This finding is consistent with previous investigations comparing preoperative and postoperative PC-MRI in CMI patients. $(7,10,18,20)$

In a study of 17 patients with CMI, Armonda et al.(10) found increased cranial and caudal velocities at the CVJ after PFD. Heiss et al. performed PC-MRI on 20 CMI patients with syringomyelia before and after PFD, and observed a significant increase in the peak caudallydirected CSF velocity at the CVJ $(1.5 \pm 0.9 \mathrm{~mL} / \mathrm{s}$ preoperatively vs. $2.4 \pm 0.9 \mathrm{~mL} / \mathrm{s}$ postoperatively; $P=0.03)$.(20) Bhadelia et al. also found an increase in cranially-directed velocity at the CVJ after PFD.(7) In contrast, Iskandar et al. studied 8 patients with CMI before and after PFD, and observed an increase in PV in 2 patients, no change in 1 patient, and a decrease in 5 patients.(21)

Previous investigators have examined a variety of techniques, both preoperative and intraoperative, to appropriately select patients for duraplasty.(16,17,22) In a retrospective analysis of 82 consecutive cases of PFD with or without duraplasty, Yilmaz et al. sought to associate preoperative MRI tonsillar ectopia measurements with postoperative outcome,(14) retrospectively stratifying patients into three grades of cerebellar tonsillar descent. Among patients with the greatest tonsillar descent (grade 3), PFDD resulted in greater clinical improvement and syrinx reduction. Among patients with milder tonsillar descent (grades 1 or 2) there was no statistically significant difference in syringomyelia cavity resolution or clinical improvement. However, the authors do not specify how patients were selected into the PFD or PFDD groups. 
Yeh and colleagues conducted a prospective study of 149 pediatric patients with CMI undergoing PFD and PFDD between 1995 and 2003.(17) After suboccipital craniectomy, ultrasound was used to assess adequate decompression, defined by CSF space anterior to the brainstem and dorsal to the cerebellar tonsils, and absence of tonsillar piston-like pulsations. If adequate decompression was not achieved, duraplasty with or without tonsillar elevation was performed. At follow-up, PFD and PFDD resulted in symptom improvement without the need for re-operation in $90 \%(n=40)$ and $98 \%(n=85)$ of patients, respectively. However, the PFDD group had a postoperative complication rate of 13.3\% (infection, pseudomeningocele, CSF leak, brainstem swelling/extended ventilation), compared to no complications in the PFD group. Although preoperative MRI was not used to guide the decision to perform duraplasty, tonsillar ectopia on preoperative MRI was, on average, $3.1 \mathrm{~mm}$ lower in the PFDD group compared with PFD.

In a study of 256 consecutive cases between 1995 and 2005, McGirt et al. used intraoperative ultrasound to guide selection of patients for duraplasty.(16) Duraplasty was performed when piston-like pulsations of the distal tonsils or loss of cerebellar systolic pulsations was observed. Among patients with tonsillar herniation caudal to C1 receiving PFD, there was a 2-fold higher incidence of symptom recurrence. Of note, re-operation with duraplasty led to symptom resolution in 7 of the 9 cases in which PFD had failed. In patients with preoperative tonsillar ectopia rostral to C1, PFDD had no significant benefit over PFD. 
The failure of intraoperative ultrasound to reliably select patients likely to benefit from PFD alone observed in the study by McGirt et al.(16) may be due to subjectivity and variability in interpreting qualitative evaluation of CSF hydrodynamics. Velocity of CSF motion at the CVJ seems to serve as an indicator of adequate normalization. In addition to furthering our understanding of pathologic CSF hydrodynamics in CMI, intraoperative MRI studies of CSF velocities may provide objective, quantitative parameters that define adequate CSF pathway restoration. With further research to determine quantitative parameters, intraoperative PC-MRI may be used to identify patients who would benefit from additional duraplasty after PFD.

Differences in age should not introduce bias in this study as changes in velocity are compared at different time-points in individual patients. CSF hydrodynamics can vary with age, as observed in the study by Iskandar and Haughton.(23) Our study does have this limitation; however, on closer assessment the age range is within the same range as in the aforementioned study. Postsurgical changes may affect CSF velocities and limit comparisons of intraoperative PC-MRI measurements and delayed PC-MRI measurements. CSF hydrodynamics may differ immediately post-decompression compared to weeks after surgery, limiting comparisons with previously reported postoperative velocity measurements.(24) Changes in CSF dynamics at the CVJ may be secondary to cerebral compliance during PFDD, and may not be an adequate measure of decompression at all.(25) Ohara et al. theorized that increased cerebral compliance is associated with higher velocities of CSF motion.(26) Bhadelia et al. observed a reduction in CSF velocities with jugular venous compression.(18) 
Differences in MRI scanners, software, acquisition protocols, and ages of the patients studied may explain the variations of CSF velocities reported in the literature.(23) In several cases with severe tonsillar ectopia and no visible CSF space posteriorly at the foramen magnum, the ROI was positioned slightly below the foramen magnum to allow for CSF velocity measurements. While this introduced slight variability between subjects, the ROI was kept at a constant level throughout pre-incision, bone decompression, duraplasty, and postoperative scans. In a study of 22 patients with CMI, CSF velocity was not found to be significantly different in the foramen compared to the C2-C3 level but became significantly higher at C3 and C4.(27) The slight variability in the level of the ROI at the CVJ was necessary to obtain CSF measurements and unlikely to affect our results. Lastly, since the studies were performed with patients under general anesthesia, a more nuanced approach to the imaging protocols could not be obtained as would have been the case in a prospective research study. Furthermore, the effect of anesthesia on CSF velocities remains unknown.

In conclusion, we report intraoperative quantitative measurement of CSF velocities in CMI patients, using PC-MRI. In 12 patients, significant increases in MV and PV of craniallyand caudally-directed velocities were observed from pre-incision to post-PFDD scans at the posterior CVJ. Our results are congruent with previously reported CSF velocities at the CVJ after PFD and PFDD.(7,10,20) Further research is necessary before intraoperative PC-MRI can be used to select patients for bone-only PFD. Specifically, CSF velocities that are closely correlated with clinical response need to be identified.

This article is protected by copyright. All rights reserved. 
This article is protected by copyright. All rights reserved. 


\section{REFERENCES}

1. Hofmann E, Warmuth-Metz M, Bendszus M, Solymosi L. Phase-contrast MR imaging of the cervical CSF and spinal cord: volumetric motion analysis in patients with Chiari I malformation. AJNR Am J Neuroradiol 2000;21:151-158.

2. Kelly EJ, Yamada S. Cerebrospinal fluid flow studies and recent advancements. Semin Ultrasound CT MR 2016;37:92-99.

3. Chiari H. Veranderungen des kleinhirns infolge von hydrocephalie des grosshirns. Deutsche Medicinische Wochenschrigt 1891;17:1172-1175.

4. Mortazavi MM, Tubbs RS, Brockerhoff MA, Loukas M, Oakes WJ. The first description of Chiari I malformation with intuitive correlation between tonsillar ectopia and syringomyelia. J Neurosurg Pediatr 2011;7:257-260.

5. Gardner WJ. Hydrodynamic mechanism of syringomyelia: its relationship to myelocele. J Neurol Neurosurg Psychiatry 1965;28:247-259.

6. Williams B. On the pathogenesis of syringomyelia: a review. J R Soc Med 1980;73:798806.

7. Bhadelia RA, Bogdan AR, Wolpert SM, Lev S, Appignani BA, Heilman CB. Cerebrospinal fluid flow waveforms: analysis in patients with Chiari I malformation by means of gated phase-contrast MR imaging velocity measurements. Radiology 1995;196:195-202.

This article is protected by copyright. All rights reserved. 
8. Aitken LA, Lindan CE, Sidney S, et al. Chiari type I malformation in a pediatric population. Pediatr Neurol 2009;40:449-454.

9. Smith BW, Strahle J, Bapuraj JR, Muraszko KM, Garton HJ, Maher CO. Distribution of cerebellar tonsil position: implications for understanding Chiari malformation. J Neurosurg 2013;119:812-819.

10. Armonda RA, Citrin CM, Foley KT, Ellenbogen RG. Quantitative cine-mode magnetic resonance imaging of Chiari I malformations: an analysis of cerebrospinal fluid dynamics. Neurosurgery 1994;35:214-223; discussion 223-214.

11. Haughton VM, Korosec FR, Medow JE, Dolar MT, Iskandar BJ. Peak systolic and diastolic CSF velocity in the foramen magnum in adult patients with Chiari I malformations and in normal control participants. AJNR Am J Neuroradiol 2003;24:169176.

12. Dolar MT, Haughton VM, Iskandar BJ, Quigley M. Effect of craniocervical decompression on peak CSF velocities in symptomatic patients with Chiari I malformation. AJNR Am J Neuroradiol 2004;25:142-145.

13. Haroun RI, Guarnieri M, Meadow JJ, Kraut M, Carson BS. Current opinions for the treatment of syringomyelia and chiari malformations: survey of the Pediatric Section of the American Association of Neurological Surgeons. Pediatr Neurosurg 2000;33:311317.

This article is protected by copyright. All rights reserved. 
14. Yilmaz A, Kanat A, Musluman AM, et al. When is duraplasty required in the surgical treatment of Chiari malformation type I based on tonsillar descending grading scale? World Neurosurg 2011;75:307-313.

15. Parker SR, Harris P, Cummings TJ, George T, Fuchs H, Grant G. Complications following decompression of Chiari malformation Type I in children: dural graft or sealant? J Neurosurg Pediatr 2011;8:177-183.

16. McGirt MJ, Atiba A, Attenello FJ, et al. Correlation of hindbrain CSF flow and outcome after surgical decompression for Chiari I malformation. Childs Nerv Syst 2008;24:833840.

17. Yeh DD, Koch B, Crone KR. Intraoperative ultrasonography used to determine the extent of surgery necessary during posterior fossa decompression in children with Chiari malformation type I. J Neurosurg 2006;105:26-32.

18. Bhadelia RA, Bogdan AR, Wolpert SM. Analysis of cerebrospinal fluid flow waveforms with gated phase-contrast MR velocity measurements. AJNR Am J Neuroradiol 1995;16:389-400.

19. Schroeder HW, Schweim C, Schweim KH, Gaab MR. Analysis of aqueductal cerebrospinal fluid flow after endoscopic aqueductoplasty by using cine phase-contrast magnetic resonance imaging. J Neurosurg 2000;93:237-244.

20. Heiss JD, Patronas N, DeVroom HL, et al. Elucidating the pathophysiology of syringomyelia. J Neurosurg 1999;91:553-562.

This article is protected by copyright. All rights reserved. 
21. Iskandar BJ, Quigley M, Haughton VM. Foramen magnum cerebrospinal fluid flow characteristics in children with Chiari I malformation before and after craniocervical decompression. J Neurosurg 2004;101:169-178.

22. Gandhoke GS, Hauptman JS, Salvetti DJ, et al. Transosseous cerebrospinal fluid fistula 14 years after Chiari decompression: presentation and management. J Neurosurg Pediatr 2015;16:146-149.

23. Iskandar BJ, Haughton V. Age-related variations in peak cerebrospinal fluid velocities in the foramen magnum. J Neurosurg 2005;103:508-511.

24. Wang CS, Wang X, Fu CH, Wei LQ, Zhou DQ, Lin JK. Analysis of cerebrospinal fluid flow dynamics and morphology in Chiari I malformation with cine phase-contrast magnetic resonance imaging. Acta Neurochir (Wien) 2014;156:707-713.

25. Sivaramakrishnan A, Alperin N, Surapaneni S, Lichtor T. Evaluating the effect of decompression surgery on cerebrospinal fluid flow and intracranial compliance in patients with chiari malformation with magnetic resonance imaging flow studies. Neurosurgery 2004;55:1344-1350; discussion 1350-1341.

26. Ohara S, Nagai H, Matsumoto T, Banno T. MR imaging of CSF pulsatory flow and its relation to intracranial pressure. J Neurosurg 1988;69:675-682.

27. Shah S, Haughton V, del Rio AM. CSF flow through the upper cervical spinal canal in Chiari I malformation. AJNR Am J Neuroradiol 2011;32:1149-1153.

This article is protected by copyright. All rights reserved. 
This article is protected by copyright. All rights reserved. 


\begin{tabular}{|cccccccc|}
\hline TABLE 1. Preoperative Mean Velocities (MV) & & & & \\
\hline Case & $\begin{array}{c}\text { Age } \\
\text { (Yrs) }\end{array}$ & Sex & $\begin{array}{c}\text { Tonsillar } \\
\text { Ectopia } \\
(\mathrm{mm})\end{array}$ & Syringomyelia & $\begin{array}{c}\text { Caudal MV } \\
\text { (cm/s) }\end{array}$ & $\begin{array}{c}\text { Cranial MV } \\
\text { (cm/s) }\end{array}$ & $\begin{array}{c}\text { Amplitude } \\
\text { of MV } \\
\text { (cm/s) }\end{array}$ \\
\hline $\mathbf{1}$ & 15 & Male & 17 & Yes & -0.844 & 0.793 & 1.637 \\
\hline $\mathbf{2}$ & 15 & Female & 10 & Yes & -2.817 & 0.31 & 3.127 \\
\hline $\mathbf{3}$ & $\mathbf{4}$ & Male & 22 & No & -1.645 & 0.675 & 2.32 \\
\hline $\mathbf{4}$ & 12 & Female & 15 & Yes & -1.353 & 0.759 & 2.112 \\
\hline $\mathbf{5}$ & 15 & Male & 12 & Yes & -1.919 & 0.934 & 2.853 \\
\hline $\mathbf{6}$ & 17 & Female & 26 & Yes & -2.608 & 1.042 & 3.65 \\
\hline $\mathbf{7}$ & 18 & Male & 22 & No & -0.96 & 0.868 & 1.828 \\
\hline $\mathbf{8}$ & 18 & Male & 18 & Yes & -0.419 & 0.293 & 0.712 \\
\hline $\mathbf{9}$ & 18 & Female & 30 & No & -0.864 & 0.967 & 1.831 \\
\hline $\mathbf{1 0}$ & 12 & Female & 10 & Yes & -1.808 & 0.526 & 2.333 \\
\hline $\mathbf{1 1}$ & 17 & Female & 26 & Yes & -3.267 & 1.602 & 4.869 \\
\hline $\mathbf{1 2}$ & 6 & Female & 16 & Yes & -2.902 & 0.672 & 3.574 \\
\hline
\end{tabular}

This article is protected by copyright. All rights reserved. 


\begin{tabular}{|cccccc|}
\hline \multicolumn{7}{|c|}{ TABLE 2. Peak Velocities at the Posterior Craniovertebral Junction (cm/s) } \\
\hline \multicolumn{7}{|c|}{$\mathrm{n}$} & Mean & SD & Minimun & Maximum \\
\hline Caudal velocity & & & & & \\
\hline Pre-incision & 12 & -3.299 & 1.747 & -6.452 & -0.836 \\
\hline Craniectomy & 10 & -4.292 & 5.173 & -17.232 & 1.584 \\
\hline Duraplasty & 7 & -3.786 & 2.736 & -8.349 & -0.897 \\
\hline Postoperative & 6 & -5.658 & 2.896 & -10.928 & -3.089 \\
\hline Cranial velocity & & & & & \\
\hline Pre-incision & 12 & 1.937 & 1.53 & 0.718 & 5.537 \\
\hline Craniectomy & 10 & 2.712 & 1.568 & 1.348 & 6.662 \\
\hline Duraplasty & 7 & 2.816 & 1.606 & 0.896 & 5.551 \\
\hline Postoperative & 6 & 3.509 & 0.6 & 2.594 & 4.294 \\
\hline Amplitude & & & & & \\
\hline Pre-incision & 12 & 5.236 & 2.931 & 1.554 & 11.144 \\
\hline Craniectomy & 9 & 7 & 6.887 & 1.84 & 23.895 \\
\hline Duraplasty & 7 & 6.602 & 4.121 & 1.793 & 12.682 \\
\hline Postoperative & 6 & 9.168 & 3.344 & 6.461 & 15.223 \\
\hline
\end{tabular}

SD, standard deviation.

This article is protected by copyright. All rights reserved. 


\begin{tabular}{|cccccc|}
\hline \multicolumn{7}{|c|}{ TABLE 3. Mean Velocities at the Posterior Craniovertebral Junction (cm/s) } \\
\hline \multicolumn{7}{|c}{$\mathrm{n}$} & Mean & SD & Minimum & Maximum \\
\hline Caudal velocity & & & & & \\
\hline Pre-incision & 12 & -1.784 & 0.939 & -3.267 & -0.419 \\
\hline Craniectomy & 10 & -1.815 & 1.385 & -3.702 & 0.404 \\
\hline Duraplasty & 7 & -1.613 & 1.033 & -3.053 & -0.302 \\
\hline Postoperative & 6 & -2.76 & 2.111 & -6.29 & -0.342 \\
\hline Cranial velocity & & & & & \\
\hline Pre-incision & 12 & 0.787 & 0.351 & 0.293 & 1.602 \\
\hline Craniectomy & 10 & 1.224 & 0.651 & 0.377 & 2.327 \\
\hline Duraplasty & 7 & 1.197 & 0.538 & 0.503 & 2.141 \\
\hline Postoperative & 6 & 1.801 & 0.992 & 0.804 & 3.41 \\
\hline Amplitude & & & & & \\
\hline Pre-incision & 12 & 2.57 & 1.112 & 0.712 & 4.869 \\
\hline Craniectomy & 10 & 3.039 & 1.768 & 0.523 & 5.778 \\
\hline Duraplasty & 7 & 2.811 & 1.363 & 0.805 & 5.194 \\
\hline Postoperative & 6 & 4.561 & 2.794 & 1.146 & 8.301 \\
\hline
\end{tabular}

SD, standard deviation.

This article is protected by copyright. All rights reserved. 


\begin{tabular}{|c|c|c|c|}
\hline & Craniectomy & Duraplasty & Postoperative \\
\hline \multicolumn{4}{|l|}{ Caudal } \\
\hline Pre-incision & 0.964 & 1.468 & $2.357^{*}$ \\
\hline Craniectomy & & 0.992 & 2.357 \\
\hline Duraplasty & & & 1.861 \\
\hline \multicolumn{4}{|l|}{ Cranial } \\
\hline Pre-incision & 0.739 & $1.676^{*}$ & $2.154^{*}$ \\
\hline Craniectomy & & 1.676 & 1.748 \\
\hline Duraplasty & & & 1.627 \\
\hline \multicolumn{4}{|l|}{ Amplitude } \\
\hline Pre-incision & 1.703 & 3.143* & $4.511 *$ \\
\hline Craniectomy & & $1.755^{*}$ & 4.061 \\
\hline Duraplasty & & & 3.488 \\
\hline
\end{tabular}

$* P<0.05$.

This article is protected by copyright. All rights reserved. 


\begin{tabular}{|c|c|c|c|}
\hline & Craniectomy & Duraplasty & Postoperative \\
\hline \multicolumn{4}{|l|}{ Caudal } \\
\hline Pre-incision & 0.002 & 0.029 & 0.896 \\
\hline Craniectomy & & -0.016 & 1.41 \\
\hline Duraplasty & & & 1.194 \\
\hline \multicolumn{4}{|l|}{ Cranial } \\
\hline Pre-incision & $0.45^{*}$ & $0.488^{*}$ & $1.049 *$ \\
\hline Craniectomy & & 0.2 & 1.586 \\
\hline Duraplasty & & & 1.252 \\
\hline \multicolumn{4}{|l|}{ Amplitude } \\
\hline Pre-incision & 0.451 & 0.517 & 1.945 \\
\hline Craniectomy & & 1.814 & 1.945 \\
\hline Duraplasty & & & 2.447 \\
\hline
\end{tabular}

$* P<0.05$.

This article is protected by copyright. All rights reserved. 


\section{FIGURE LEGENDS}

Figure 1: Sagittal T2-weighted image (left) used as a localizer for selection of a scan plane for the phase contrast axial image (right). Arrow indicates the posterior pocket of CSF selected for velocity analysis. (a) These images were obtained prior to surgery in the intraoperative suite. Note that the plane selected in this patient is just below the tip of the descended tonsil. (b) These images from the same patient were obtained after osseous decompression in the intraoperative suite. Note the relative change in the size and shape of the space. Note the scan plane corresponds to the plane shown in panel a.

FIGURE 2: Screen grab of the region of interest placed in the posterior subarachnoid space with the corresponding readout, taken in a different patient. 
a

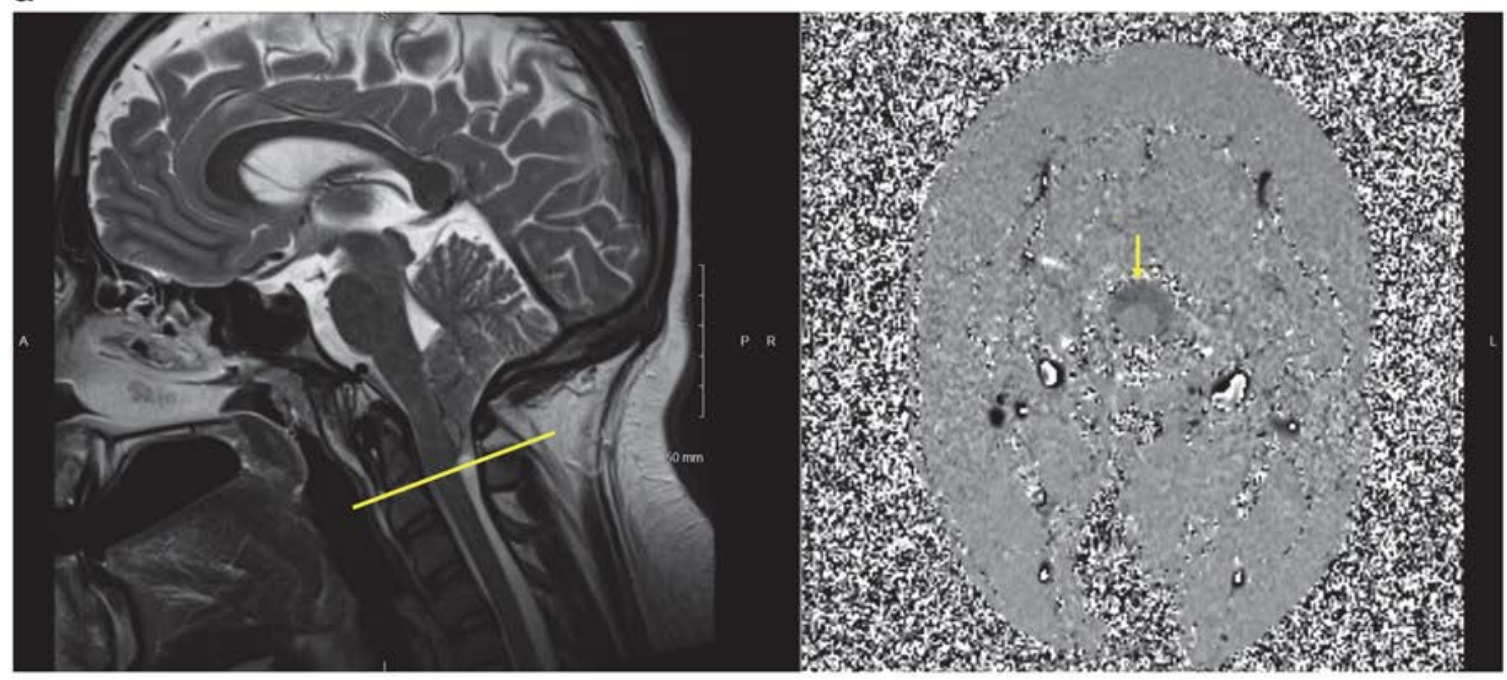

b

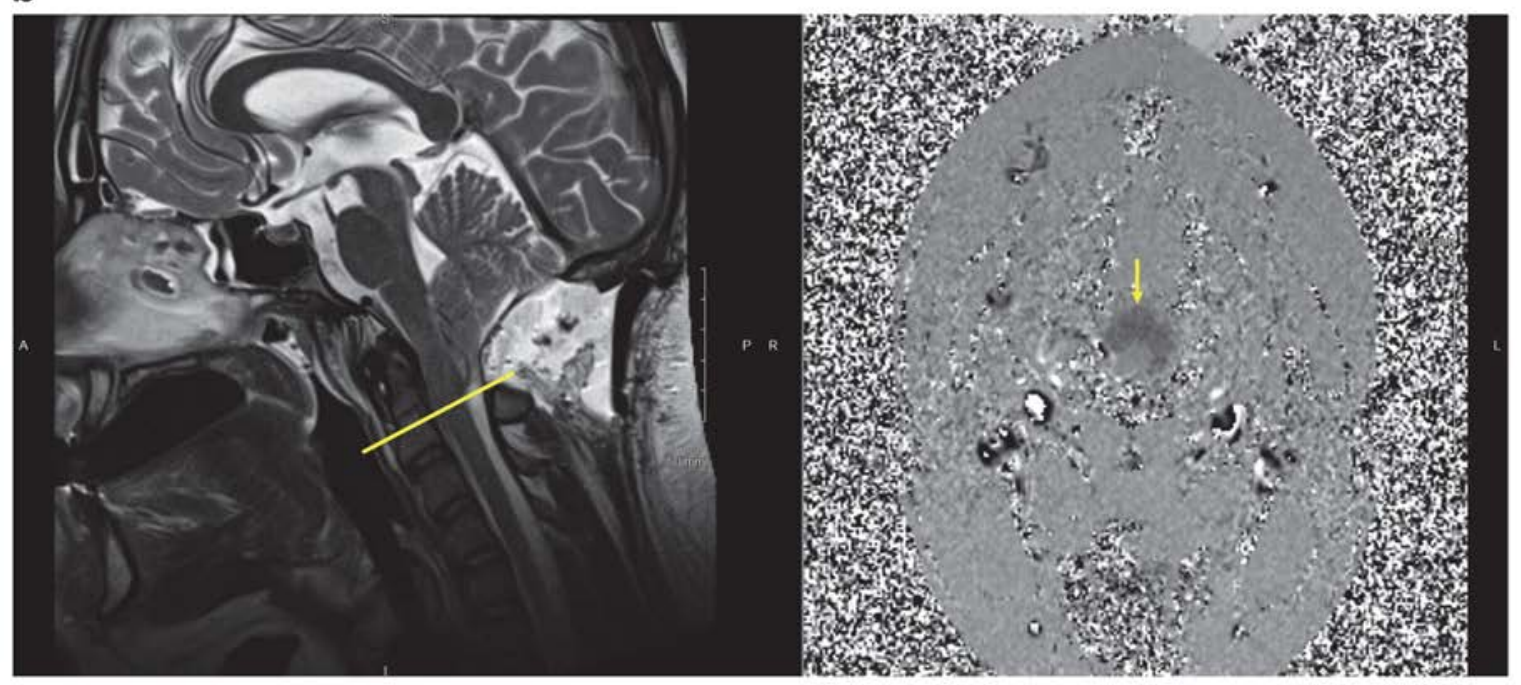

Figure 1: Sagittal T2-weighted image (left) used as a localizer for selection of a scan plane for the phase contrast axial image (right). Arrow indicates the posterior pocket of CSF selected for velocity analysis. (a) These images were obtained prior to surgery in the intraoperative suite. Note that the plane selected in this patient is just below the tip of the descended tonsil. (b) These images from the same patient were obtained after osseous decompression in the intraoperative suite. Note the relative change in the size and shape of the space. Note the scan plane corresponds to the plane shown in panel $\mathbf{a}$. 
This article is protected by copyright. All rights reserved. 


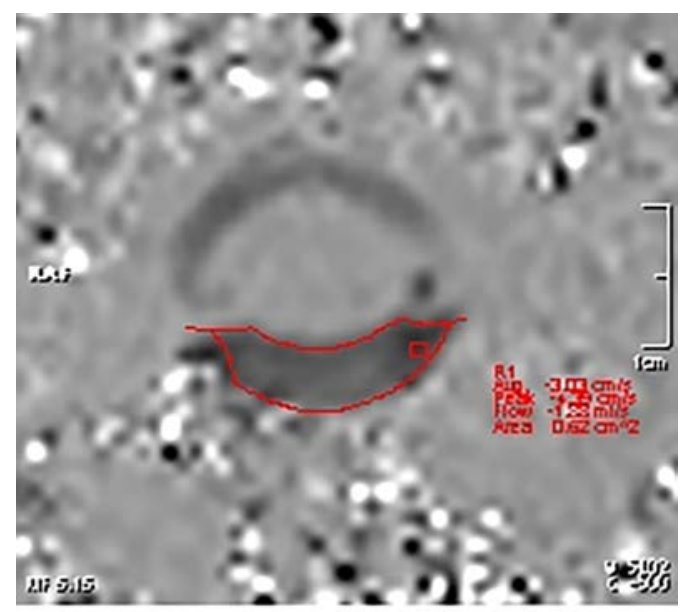

Figure 2: Screen grab of the region of interest placed in the posterior subarachnoid space with the corresponding readout, taken in a different patient. 

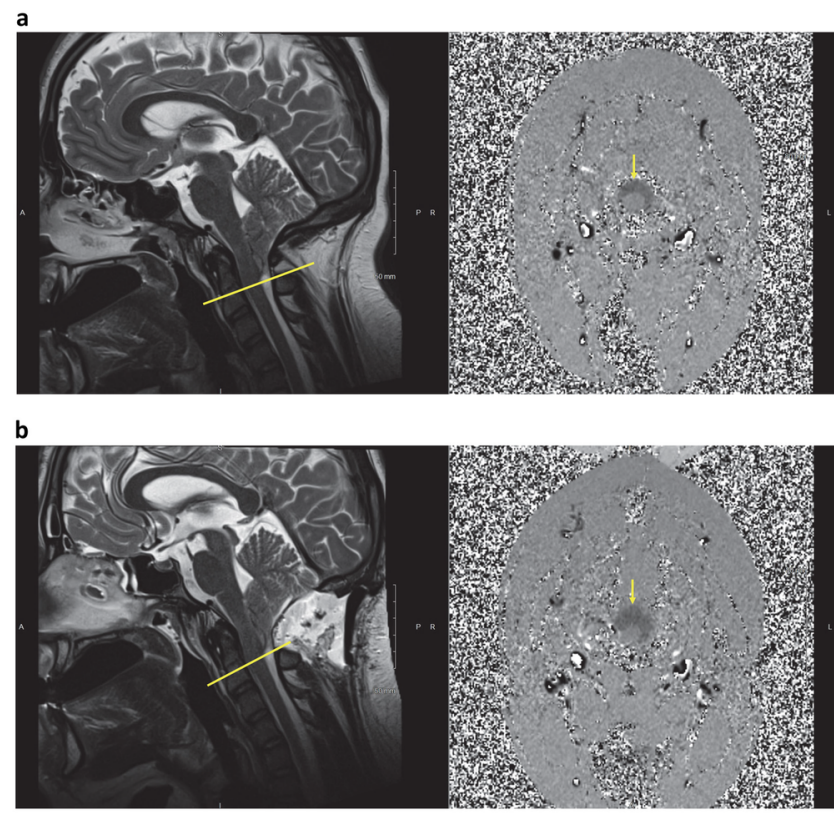

Figure 1: Sagittal T2-weighted image (left) used as a localizer for selection of a scan plane for the phase contrast axial image (right). Arrow indicates the posterior pocket of CSF selected for velocity analysis. (a) These images were obtained prior to surgery in the intraoperative suite. Note that the plane selected in this patient is just below the tip of the descended tonsil. (b) These images from the same patient were obtained after osseous decompression in the intraoperative suite. Note the relative change in the size and shape of the space. Note the scan plane corresponds to the plane shown in panel a.

\section{JMRI_26953_Fig1.tif}




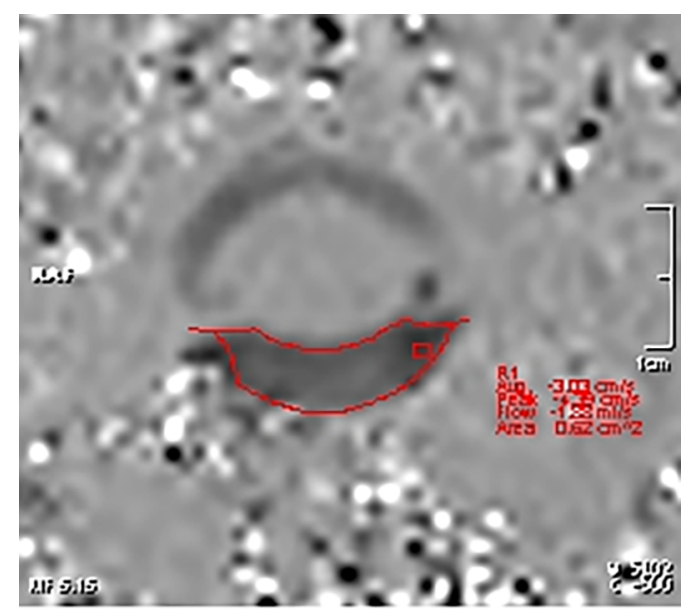

Figure 2: Screen grab of the region of interest placed in the posterior subarachnoid space with the corresponding readout, taken in a different patient.

JMRI_26953_Fig2.tif

This article is protected by copyright. All rights reserved. 